Post, R. M., Denicoff, K. D., Frye, M. A., et al (1997) Reevaluating carbamazepine prophylaxis in bipolar disorder. British journal of Psychiatry, 170. 202-204.

Robert, G. \& Kennedy, P. (1997) Establishing costeffectiveness of atypical neuroleptics. British journal of Psychiatry, 171, 103-104.

Sudip Sikdar Oakdale Unit, Fazakerley Hospital Longmoor Lane, Liverpool L92 7AL

\section{Lithium: evidence reconsidered}

Sir: In re-evaluating lithium augmentation studies Joanna Moncrieff (1997) quotes our study, but appears not to have read it. She writes "The largest and longest of them [lithium augmentation studies], which followed up 34 patients for three weeks, was negative (Stein \& Barnadt, 1988)", whereas we actually reported on 24 patients followed up for nine weeks and that there were significant lithium augmentation effects at weeks three, six and nine.

The reason we then reported on 24 patients, which was three-quarters of the way through the trial, was the occurrence of the Second British Lithium Congress, which we regarded as an important occasion. Our final and definitive report (Stein \& Bernadt, 1993) which Dr Moncrieff did not quote was of 34 patients who over a nine-week trial showed significant benefit from lithium augmentation for treatment-resistant depression. We found that when added to existing tricyclic medication, which was taken in maximally tolerated doses, lithium $750 \mathrm{mg}$ per day had a greater antidepressant effect than low-dose lithium $(250 \mathrm{mg}$ per day), which was no better than placebo. Dr Moncrieff also states that our earlier study reported low compliance rates, but neither of our publications mentioned compliance and our impression was of good compliance. The review is also inaccurate in stating that ours is the largest lithium augmentation study in that Katona et al (1995) had 61 patients. Another study that should have been quoted is Dinan \& Barry (1989) who showed that lithium augmentation was as effective as electroconvulsive therapy in tricyclic non-responders.

Dr Moncrieff is right to draw attention to methodological weaknesses in lithium studies. Because lithium treatment is cheap, research about it has never attracted funding of the scale lavished on the newer antidepressants and there remain important uncertainties about its clinical use.

Dinan, T. G. Barry, S. (1989) A comparison of electroconvulsive therapy with a combined lithium and tricyclic combination among depressed tricyclic nonresponders. Acto Psychiatrica Scondinavica, 80, 97-100.

Katona, C. L. E., Abou-Saleh, M. T., Harrison, D. A., et al (1995) Placebo-controlled trial of lithium augmentation of fluoxetine and lofepramine. British journol of Psychiatry. 166. 80-86.

Moncrieff, J. (1997) Lithium: evidence reconsidered. British journal of Psychiatry, 171, 113-119.

Stein, G. \&ernadt, M. (1988) Double blind trial of lithium carbonate in tricyclic resistant depression. In Lithium: Inorganic Pharmocology and Psychiatric Use (ed. N. J. Birch). Oxford: IRL Press.

- _ (1993) Lithium augmentation therapy in tricyclic resistant depression. A controlled trial using lithium in low and normal doses. British fournol of Psychiatry. 162, 634-640.

M Bernadt, G. Stein Department of Psychological Medicine, King's School of Medicine and Dentistry. 103 Denmark Hill, London SE5 8AZ

\section{Grey matter correlates of syndromes in schizophrenia}

Sir: In a sample of people with schizophrenia Chua et al (1997) reported the interesting finding that there was a significant and positive correlation between the disorganisation score and relative volumes of grey matter in medial temporal lobe structures. They mention that this finding "may seem at odds with the reportedly reduced size of this region in schizophrenia. However, our observations were made within a group of schizophrenics, and reflected differences among schizophrenics rather than differences between schizophrenics and controls". They proceeded to discuss reasons why increased volume of grey matter in medial temporal lobe structures might result from some pathological process in schizophrenia, for example, lack of neuronal pruning.

There is another possible interpretation which may be somewhat more parsimonious. It is possible that the finding reflects normal volume of medial temporal lobe grey matter in patients with the disorganisation syndrome, and abnormal reductions of temporal lobe grey matter in other people with schizophrenia. This interpretation is consistent with many studies which have found that the volume of medial temporal lobe grey matter is abnormally reduced in schizophrenia (Suddath et al, 1990; Breier et al,
1992; Rossi et al, 1994; Fukuzako et al, 1996). It is also consistent with a previous report of an association between reduced mesiotemporal tissue volume and higher ratings of the Brief Psychiatric Rating Scale psychosis factor (Bogerts et al, 1993).

Hypotheses based on these alternative interpretations could be tested in future studies by including a normal comparison group.

Bogerts, B., Lieberman, J. A., Ashtari, M., et al (1993) Hippocampus-amygdala volumes and psychopathology in chronic schizophrenia. Biological Psychiatry, 33. 236-246.

Breier, A., Buchanan, R., Elkashef, A., ot ol (1992) Brain morphology and schizophrenia. A magnetic resonance imaging study of limbic, prefrontal cortex, and caudate structures. Archives of General Psychiatry, 49, 921-926.

Chua, S. E., Wright, I. C. \& Poline, J. B. (1997) Grey matter correlates of syndromes in schizophrenia. A semi-automated analysis of structural magnetic resonance images. British Journal of Psychiotry, 170, 406-410.

Fukuzako, H., Fukuzako, T., Hashiguchi, T., et al (1996) Reduction in hippocampal formation volume is caused mainly by its shortening in chronic schizophrenia: assessment by MRI. Biological Psychiatry, 39, 398-945.

Rossi, A., Stratta, P., Mancini, F., et ol (1994) Magnetic resonance imaging findings of amygdala-anterior hippocampus shrinkage in male patients with schizophrenia. Psychiatry Reseorch, 52, 43-53.

Suddath, R. L., Christison, G.W., Torrey, E. F., et al (1990) Anatomical abnormalities in the brains of monozygotic twins discordant for schizophrenia. New England journal of Medicine, 322, 789-794.

David E. Rous Maryland Psychiatric Research Center. University of Maryland at Baltimore, PO Box 21247, Baltimore, MD 21228, USA

\section{Comorbidity of mental disorders with substance misuse}

Sir: A recent editorial in the Journal on comorbidity of mental disorders with substance misuse proposed that staff in addiction services should be trained to identify anxiety and affective disorders in their clientele (Hall \& Farrell, 1997). A third of persons with an alcohol use disorder $(37 \%)$ have another mental disorder and half of those with other drug use disorders have comorbid mental disorder (Regier et al, 1990). Purchasers are increasingly using services provided by non-statutory agencies, which are often cheaper than those provided by psychiatric addiction services, in part because there is less emphasis on nursing and psychiatric training within the staff skills mix. 